\title{
Identidade, transnacionalidade e fronteira entre os Chiquitanos: A Procissão de Santa Ana
}

\author{
Graduando Gustavo dos Santos Teles \\ Universidade Federal de Goiás \\ gustavo.steles@gmail.com
}

\section{RESUMO}

O objetivo desse artigo é realizar uma análise de um ritual presente no imaginário de comunidades do povo Chiquitano na Bolívia e no Brasil. A procissão de Santa Ana, realizada anualmente como iniciativa da comunidade de Santa Ana constitui o objeto de estudo, que só se faz palpável ao retomarmos as construções históricas desse povo, que trazem a tona, relações de poder que atuaram em sua construção identitária.

Esse processo de retomada de fontes históricas está aliado ao um exercício teórico de se pensar esse povo sob a ótica de duas fronteiras nacionais. Analisar como a fronteira atua como espaços de ruptura e conflito, elaborando originalidade pela multiplicação da experiência e realizando modificações espirituais e como a transnacionalidade atua na relação entre territórios e diferentes arranjos sócio- culturais e políticos. A busca é então pensar a maneira como o povo Chiquitano representa pertencimento a unidades sócio-culturais.

\section{ABSTRACT}

The aim of this study is to analyze a ritual Chiquitano people in Bolivia and Brazil. The procession of Santa Ana, held annually as an initiative of the community of Santa Ana is the object of study, which only becomes palpable with a historical return of people bringing to light, the power relations that they acted on their identity. This process of retrieving historical sources is coupled to a theoretical exercise to think people from the perspective of two borders. Examine how the boundary acts as spaces of conflict and disruption, originally given by multiplying the experience and make changes and serves as spiritual transnational relations between regions and different socio-cultural arrangements and politicians. The search is then think like the people Chiquitano represents adherence to socio-cultural unity.

A história do povo Chiquitano está indissociavelmente ligada a políticas de consolidação de fronteiras nacionais nos séculos XVI e XVII na Bolívia e Brasil. O que se faz de grande importância nesse período de colonização luzo - espanhola, 
é a implantação das missões jesuítas no território boliviano. O discurso colonial busca apresentar o colonizado como uma população de tipos degenerados e com base na origem racial seu objetivo é justificar a conquista e estabelecer sistemas de administração e instrução. Mais tarde, identidades se recriariam constantemente e um amálgama de povos da Missão de Chiquitos viria a desempenhar o papel de guardiões da fronteira.

Segundo Bhabha (2007) os debates de fronteira acerca da diferença cultural tem tanta possibilidade de serem consensuais quanto conflituosos, podem confundir nossas definições de tradição e modernidade, realinhar fronteiras habituais entre público e privado, assim podem desafiar as expectativas de desenvolvimento e progresso. Luís Sérgio (2005) procura na teoria da fronteira em Deleuze, partindo de sua definição da filosofia como disciplina criadora de conceitos, uma dimensão pensada como espaços de ruptura e conflito, elaborando originalidade pela multiplicação da experiência e realizando modificações espirituais. Jose de Souza Martins (1997) observa a fronteira como frente de expansão - alguns estudiosos entendem esse termo como situação de contato, da sociedade nacional sobre territórios ocupados por povos indígenas, como cenário altamente conflitivo onde sociedades se formam, se desorganizam ou se reproduzem. É uma complicada combinação de tempos históricos em processos sociais que recriam formas de dominação e formas de reprodução ampliada do capital, inclusive a escravidão. Acredito que o que há de mais relevante para caracterizar a fronteira é a situação de conflito; representada pela descoberta e pelo desencontro de temporalidades históricas que se dão no lugar de encontro, de alteridade. Esse conflito se faz presente por exemplo ao se relacionar proprietários de terra com indígenas, ou seja, o conflito é decorrente das diferentes concepções de vida e visões de mundo de cada um desses grupos humanos.

Fronteiras são a vitória da contigência, estabelecem o devir, o tornar-se, são zonas cinzentas, onde os contornos são mal definidos. Essas problemáticas envolvem com frequência antagonismos e contradições entre diferentes atores que encenam em um mesmo espaço transnacional.

As dimenssões desse espaço transnacional transcendem as fronteiras entre estados nacionais, incorporam temáticas como globalização, sistema mundial e divisão do trabalho, mas o que tomaremos significativo para se pensar o povo Chiquitano reside nas idéias de Gustavo Lins (1997) no que se refere a uma questão central a relação entre territórios e diferentes arranjos sócio culturais e políticos que orientam a maneira como as pessoas representam pertencimento a unidades sócio-culturais, isto é orientam a consciência de fazer parte de um corpo identitário específico. Esse referencial esboçado 
por Gustavo Lins, que toma como plano de fundo o processo de expansão do sistema capitalista, em que a sobreposição de territórios é condição a sua existência, nos serve como aparato para pensar a destribuição desigual de poder que podemos observar na história do povo Chiquitano.

A trajetória de formação identitária do povo Chiquitano, cujo território estendese entre o estado de Mato Grosso e a maior parte dele localizados entre os $14^{\circ}$ e $19^{\circ}$ de latitude sul, no Oriente Boliviano (ver anexo 1), é preconizada por relações interétnicas conturbadas. Esta impossível de ser pensada sem antes resgatarmos o período missional da colônia espanhola. A região onde habitavam os Chiquitos e outras etnias que mais tarde constituiriam o povo Chiquitano fez parte dos caminhos percorridos por exploradores espanhóis que buscavam povoar a região do Rio da Prata em busca dos lendários tesouros do Paytiti, do El Dorado e da Sierra de la Plata.

Ao efetuarem as entradas pelas vias naturais que conduzissem ao El Dorado, os exploradores buscavam caminhos de menor resistência, mostrando-se imprescindível o estabelecimento do domínio das terras, atuando em defesa de ataques de índios hostis e consolidando uma rede de logística nescessária as expedições. Em 1543 a fundação de Puerto de los Reyes na região do alto Paraguai, por Domingos Martinez de Irala, propiciou o suporte adequado a penetração rumo oriente. Em companhia de Nuflo de Chavez o capitão Irala organizou uma segunda expedição, que ao cruzar o rio Grande, se deparou com índios que dominavam o idioma castelhano, a região estava também sendo explorada pelo vice-reinado do Peru. Após enfrentar "un terrible combate con más de vinte mil indios tupuimiries o chiquitos posuedores del secreto de la yerba“ (GANDIA, 1929, p.122) Nuflo de Chavez continuou com o objetivo inicial de estabeleçer a primeira povoação em território Chiquito. Em 1559, próximo ao rio Grande e da lagoa de Mapá, posteriormente em fevereiro de 1561, instalou-se mais ao sul, no lugar que viria a ser a cidade de Santa Cruz de La Sierra e que dois séculos depois estaria próximo a Missão de San José dos Chiquitos.

Fica claro que desde o início da história da colonização espanhola na região, o propósito de consolidação de laços econômicos desempenhava papel central, mais a frente vislumbraremos esse propósito aliado ao ideal de consolidação das fronteiras de dois estados nacionais.

O processo de ocupação espanhola do oriente boliviano retrata a saga da cidade andarilha de Santa Cruz de La Sierra, ora se mudando para outra região, ora fundindo a outras cidades, padecendo de uma trajetória um tanto quanto conturbada, carregada de tensões, disputas e a extinção de dezenas de etnias. A organização do espaço do altiplano boliviano, lugar este que se tornaria o definitivo para a cidade de 
Santa Cruz de La Sierra, mostra a demanda de consumo pelo mercado mineirador e consequentemente de um sistema econômico agrícola atrelado sobretudo ao fornecimento de escravos indígenas. A resistência dos Chiquitos, muitas vezes de forma isolada e em algumas ocasiões articulada com outras etnias, acarretou em constantes conflitos e conferiu a fama de guerreiros temidos, pricipalmente por possuirem o domínio de um veneno comumente utilizado em flechas. Com o descobrimento do antídoto para as flechas, por parte dos espanhóis e do crescente número de assaltos praticados pelo Chiquitos em função de obter ferramentas, os espanhóis viram nesta situação de descenso populacional crescente uma oportunidade para a implenentação das missões. Os espanhóis vislumbravam na implementação das missões uma forma de conter as excursões dos bandeirantes portugueses e a consolidação da fronteira da coroa espanhola. Mestre em Geografia Cultural e Indigenísta da Fundação Nacional do Índio José Eduardo Fernandes Moreira da Costa comenta que:

\begin{abstract}
"O avanço dos bandeirantes constituiu um elemento importante para mudança da política de ocupação do Oriente boliviano, por colocar em risco a possessão espanhola naquelas passagens. Assim, os Chiquitos se apresentaram como aliados estratégicos na defesa do espaço colonial, capazes de obstar uma possível expansão dos domínios portugueses; mesmo porque a Coroa não estava em condições de enviar tropas regulares para guarnecer uma fronteira tão ampla. Diante dessa situação adversa, forçou o governo de Santa Cruz a alterar, em parte a lógica econômica local, fundada no escravismo indígena, ao convencer o fesuíta José Arce, do Colégio Tarija, de se incumbir primeiro catequese dos Chiquitos, postergando sua pretensão de trabalho missioneiro com os Chiriguanos. Evangelizar e armar os índios Chiquitos, transformando-os em súditos efetivos da Coroa Espanhola."
\end{abstract}

Tal era a situação do povo Chiquitano que perceber as missões como um local de proteção se tornou estratégia de sobrevivência desse povo, se entendiam seguros sob a tutela da Companhia de Jesus. A defesa do Oriente boliviano chegou a um ponto em que a alternativa a execução desse propósito somente se faria completa com a permição e preparação do indígenas para o uso de armas de fogo na missões.

As fundações das missões de San Miguel (1721), San Ignácio de Chiquitos (1748), San Tiago (1754), Santa Ana (1755) e San Corazón (1760), ocorreram após significativo período de estabelecimento da primeiras missões, assim os padres puderam dispor de um verdadeiro exército de índios convertidos ao cristianismo, construído ao longo de décadas nas reduções. O sistema missional contava nesse período com uma organização social e econômica em pleno desenvolvimento com sólida qualificação sacerdotal e universitária, observamos que esse modelo construiu laços simbólicos que perpassaram varios séculos e moldaram o cotidiano desses povos ao ponto de uma formação musical ocidental se estabelçer como traço identitário determinante na missão de Santa Ana.

Esse contato entre etnias e com os modelos homogeinizadores importados da 
metrópole espanhola, decorrente do aldeamento de diferentes povos e da instituição das missões, construiu uma consciência plena de uma identidade, de modo que fora dessa experiência não poderia ter sido concebida com tal autenticidade. A mudança estrutural, tomando como base Raymond Firth(1974), não pode ser efetuada pela atividade individual, ou seja essa mudança é produto de interações sociais.Tomichá ressalta a importância dessa construção ao passo que a experiência reducional levada a cabo pelos religiosos jesuítas durante os setenta e seis anos de permanência (1691-1767) tornou possível à formação de uma específica mentalidade cultural e religiosa aos nativos de língua chiquita, fora da experiência cristã nas reduções, antes do período dito, segundo parece, existiam na região simplesmente "nações chiquitas", sem uma autoconsciência plena de identidade étnica.

Três motivos fundamentais a respeito do processo de colonização espanhola podem ser destacados: 1) interesse do colonizador em enriquecer, 2) consolidação do domínio da Coroa espanhola, 3) o propósito do "universalismo religioso".

No que se referem ao império espanhol, às missões como "instituição da fronteira" foram característica da colonização ibérica em muitas regiões. No caso do povo Chiquitano o apoio mútuo da "Cruz e da Coroa" reuniu vários grupos remanescentes dos: Samucos, Paikoneka, Saraveka, Otuke, Kuruminaka, Kuravé, Koraveka, Tapiis, Korokaneka, Manacica e Paunaka (Meireles, 1989), em um conjunto de povos aldeados, chamados: Missão de San Xavier, Missão de San Rafael, Missão de San Jose, Missão de Miguel, Missão de San Inácio de Zamucos, Missão de Santa Ana, Missão de Santo Coração de Jesus e Missão de Santiago de Chiquitos, denominados genericamente de Missão de Chiquitos. Observamos ao longo desse processo o surgimento de uma dupla hegemonia: dos Chiquitanos e dos jesuítas, que sobrepuseram outras famílias lingüísticas e etnias, desse modo povos passaram as ser identificados como Chiquitanos e a se auto-identificar como tal.

Em detrimento de um propósito homogeneizador das missões, a experiência forjou uma identidade comunitária, associando elementos da religião cristã a uma língua comum e construindo uma identidade. Os temas mais recentes da pesquisa apontam para a problemática da identidade étnica, nacionalidade e fronteira, abordando um momento de grande discussão de um fenômeno histórico denominado globalização. Segundo SILVA (2002), a respeito das conseqüências do processo de construção identitária, "É importante salientar que esse povo viveu até muito recentemente em uma intersecção entre dois países, em uma área com limites que sofreram variações, e que a atribuição de sua identidade e de sua nacionalidade foi e tem sido manipulada em função de interesses econômicos e políticos". Este contato abriu caminho para que 
em anos mais tarde, nações, territórios, culturas e identidades se desintegrassem e se recriassem constantemente.

A trajetória do povo Chiquitano em meio à intensa exploração de mão de obra e posteriormente na participação em guerras entre estados nacionais, refletiu em um deslocamento, dentro de seu território, de algumas famílias para o lado brasileiro com intuito de proteger-se da fome, epidemias e do alistamento obrigatório. Isso conferiu ao povo Chiquitano denominações nefastas e negadores de cidadania dentro de seu próprio território, o termo bugre e boliviano os identifica como estrangeiros adquirindo aspecto pejorativo, devido a essa situação a população que vive em território brasileiro não aprecia falar de suas origens, "índio" é sempre o vizinho.

“A discussão que se impõe, portanto, é a de que identidade, nacionalidade e fronteira cruzam-se aqui de uma maneira indissociável. Para entender como ocorre este processo - negação da identidade - é necessário recuperar a história dos Chiquitanos e entender suas relações com os "brasileiros" da fronteira do Brasil com a Bolívia." (SILVA, 2001). Esse processo de formação identitária interpela relações interétnicas entre estados nação, movimenta-se entre tradições e deslocamentos e a diferentes formas de ocupação do território Chiquitano influenciam a costura entre identidade, nacionalidade e fronteira.

A localização estratégica da Missão de Santa Ana, na confluência dos caminhos as missões de San Rafael, San Miguel e San Ignácio, e sua proximidade com a fronteira luso-espanhola, aliado a maior população de indígenas catequisados proveniente das quatro missões citadas, possibilitou a formação de um centro de convergência religiosa e política. Mesmo com o trabalho de missioneiros indígenas atuando no estabelecimento de relações de aliança entre diferentes etnias, essa catequese feita por indígenas foi incentivada pelos jesuítas e atuava mesclando um antigo costume dos Chiquitos em capturar inimigos como forma de obterem prestígio e escravos, antigos laços simbólicos não foram deixados totalmente de lado. Imagens de oráculos que exerciam um importante papel na vida desses povos ficavam reclusas em um casa especialmente edificada pela comunidade e festas eram realizadas regularmente em sua homenagem. A assimilação da simbologia cristã não foi tão dificil tanto para os jesuítas como para os índios.

Durkheim (2001) é quem nos fornece inicialmente o referencial da construção teórica sobre a religião, não como uma espécie de acesso a algo misterioso, impenetrável à razão, mas existindo como uma constante busca em explicar e exprimir não o que há de anormal, excepcional nas coisas, mas o que elas têm 
em constante e regular. Observamos uma função social muito bem delineada, a de manter o curso normal da vida, um todo formado por partes, sistema mais ou menos complexo de mitos, dogmas, ritos e cerimônias. Tomemos como base assim o propósito homogeneizador como função constitutiva de uma identidade dentro da experiências das missões em território boliviano. Atuam como função social e cujas crenças que cercam esse propósito se mostram como regras de conduta, prescrevendo comportamentos indivíduais perante as coisas sagradas, agindo como manutenção a ordem natural civilizada. Todo esse sistema de doutrinas e promessas que por um lado explicam fenômenos do mundo e forjam uma identidade étnica, no caso do povo Chiquitano, por outro lhe garantem que uma providência cuidadosa velará por sua vida e o compensará, numa existência futura.

Os ritos religiosos cristãos eram ministrados de modo a despertar interesse e admiração dos índios, recursos extraordinários, como a musicalidade, eram empregados junto a distribuição de pequenos mimos católicos aos mais receptivos à conversão. Aos poucos foi se constituindo um espaço sagrado, algumas das antigas rancharias das reduções se transformaram em sede de novas missões, como em Santa Ana.

O sagrado foi alterando a paisagem e registrando a presença permanente das missões enquanto instituição religiosa dotada de templos suntuosos e as mais distintas funções religiosas se estabeleceram enquanto referência regional. Santa Ana ainda mantém uma estrutura de poder originária da antigas missões jesuíticas, constituida por um Cabildo Indígena, e cujas funções está em se encarregar dos preparativos da Festa da Padroeira. Atualmente a procissão é organizada por um pequeno grupo de missioneiros, que parte de Santa Ana em direção a fronteira com o Brasil. Em posse da imagem da santa padroeira, visitam comunidades e fazendas agregando devotos ao longo do caminho.

Uma pessoa figura como papel imprescindível a realização da peregrinação e na realização de serviços religiosos: "O Guardián de la Igreja", Don Luiz como é conhecido (Ver Anexo 2), figura cativante, excelente músico, entoador de cânticos em Chiquitano e cura leigo experiente. Principal responsável pelos festejos, Don Luiz é personagem central de liderança e atuação espiritual na comunidade.

A procissão de Santa Ana acontece desde de 1925, os peregrinos possuem um roteiro preestabelecido na procissão do ano anterior, no qual passam a viver em um espaço e tempo sagrado ao longo de quase dois meses, iniciada em maio e com fim no mês de julho. A iniciativa surge em 1925 de Ruan Soriocó, então cacique-geral de Santa Ana e de se filho José Maria Soriocó, fruto da nescessidade de suprir carência 
econômica da paróquia em manter as atividades festivas e cerimôniais. O percursso, pré estabelecido na viagem anterior, perpassa comunidades e propriedades na Bolívia e depois passam a visitar as situadas exclusivamente no Brasil, para em seguida atravessar a fronteira e retornar para Santa Ana. José Eduardo Fernandes Moreira da Costa comenta que:

"A existência da prática da dádiva nas comunidades Chiquitano, que se exerce por meio e sob a forma de partilha, constitui em importante fator de coesão social, responsável pela movimentação de bens, serviços, de convites e de outras coisas possíveis de circularem".

Segundo Mauss (1974), cabe á dádiva a produção de vínculos sociais, de solidariedade e compromisso, de relações de reciprocidade, que se manifestam de diversas formas de trocas e prestações, como uma regra que elege a obrigação de dar, receber e de retribuir.

O recebimento da procissão na casa de um membro da comunidade é, por princípio facilitada a todos os demais e propicia aos chefes de família a oportunidade de demonstrar generosidade e obter prestígio social e político. É durante esse momento sincrético, que em muitos casos, a recepção da procissão vincula-se a ao pagamento de promessas, é certo que as famílias almejam a visita da santa, comumente é ligada ao oferecimento da chicha fermentada ou aguardente insdustrializada aos presentes. Em Santa Ana, o espaço sagrado é o lugar onde se encontra a imagem da santa (ver anexo 4), onde simbologia e rituais possibilitaram a ligação entre os Chiquitano e o divino, o espaço profano compreende a área externa à igreja reservada ao comércio, lazer e as habitações.

As festas religiosas reanimam os indivíduos e a comunidade periodicamente, atuam como forças nescessárias para enfremtamento das adversidades, tanto no nível físico com espiritual. Durkheim (2000) ressalta a importância das cerimônias religiosas em mobilizar a coletividade para encontros sazonais, o reavivar da sociedade não pode ser concebido fora de uma reunião da mesma, as exigências da vida não permitem o permaneçer em estado de congregação, o dispersar é exercício comum as sociedades humanas, portanto ela se dispersa para reunir-se novamente. Essa alternância corresponde as tempos sagrados e profanos.

No caso Chiquitano podemos destacar um fenômeno que perpassa o período da procissão, a minca ou metósh, que pode ser traduzido como o mutirão brasileiro, este somente se faz presente enquano congregação de indivíduos, aproxima de uma celebração coletiva e gera obrigação de reciprocidade entre os envolvidos. Mircea Eliade (2008) ressalta que as reatualizações periódicas dos gestos divinos, as festas religiosas, voltam a ensinar os homens as sacralidades, os participantes saem de seu 
tempo histórico, constituido pela soma de eventos profanos, pessoais e intrapessoais e reúnem-se no tempo que pertence a eternidade, sagrado. O eterno presente dos acontecimentos míticos atuam como instituição fundante do tempo histórico. O objeto dessa pesquisa não está preocupado em trazer a tona discussões a respeito das noções de tempo para o povo Chiquitano, utilizo desse referencial para pensar as festas religiosas enquanto dimensão sagrada da existência e compreender o significado religioso da repetição de gestos divinos.

O referencial teórico que utilizo para pensar a procissão de Santa Ana enquanto ritual se insere na tradição da antropologia ritual ao retomar os escritos de dois autores. Inicialmente Mariza Peirano (2003) pensa o ritual como um sistema cultural de comunicações simbólicas, constituído por sequências ordenadas e padronizadas de palavras e atos. Seus traços constitutivos podem elucidar três sentidos: performático, no sentido da experimentação de performances e no sentido dos valores criados e reinterpretados durante a cerimônia. $\mathrm{O}$ ritual assim definido torna-se um longo processo de reflexão com poder de iluminar, realçar uma gama de ideais e valores que fora dessa experiência não seriam concebidos como tal. Por fim Victor Turner (1974) observa o ritual como uma conduta formal prescrita em situações não cotidianas e profundamente relacionada com crenças e forças míticas, que se reorganizam espontaneamente conferindo sentimento de pertencimento a uma coletividade.

Os referenciais teóricos que procurei retomar ao longo do curso de projeto, ora para pensar a construção identitária do povo Chiquitano, permeada por relações de poder, ora redimensionando um ritual que perpassa dois estados nacionais, nos permite pensar esse processo sob a ótica Said (2008), que concebe essa experiência ocidental européia baseada numa distinção ontológica e epistemológica feita entre o "Oriente" e o "Ocidente", e procura examinar essas distinções enquanto reflexo de relações de poder, valorizando o ocidental como instituição para governar, reestruturar e ter autoridade sobre o Oriente.

Referencias bibliográficas:

BHABHA, Homi K. O local da cultura. Belo Horizonte: Editora UFMG. Universidade Federal de Minas Gerais, 1998. 
CARDOSO DE OLIVEIRA, Roberto. "Tempo e Tradição: interpretando a antropologia” In. O Trabalho do Antropólogo. Brasília: Paralelo 15. 1998. . "O Trabalho do antropólogo: olhar, ouvir e escrever" In. O Trabalho do Antropólogo. Brasília: Paralelo 15. 1998. . "Do Índio ao Bugre". Rio de Janeiro: Francisco Alves, 1976.

COSTA, José E. F. Moreira da. A coroa do Mundo: religião, território e territorialidade Chiquitano. Cuiabá: editora da UFMT, 2006.

DUARTE, Luís Sérgio. O conceito de fronteira em Deleuze e Sarduy. In. Textos de História, v.13, n.1/2, Goiânia, UFG. 2005

DURKHEIM, Emile. "Capítulo I - As crenças propriamente totêmicas" In. As formas elementares da vida religiosa: o sistema totêmico na Austrália. Livro.II. 2. ed. São Paulo : Paulus, 2001. . "Definição do Fenômeno Religioso e da Religião" In. As formas elementares da vida religiosa: o sistema totêmico na Austrália. Livro.I. 2. ed. São Paulo : Paulus, 2001.

ELIADE, Mircea. O sagrado e o Profano. São Paulo: Martins Fontes, 2008.

MALDI, Denise. Guardiães da Fronteira, Rio Guaporé, século XVIII. Petrópolis: Vozes, 1989.

MARTINS, José de Souza. Fronteira: A degradação do Outro nos confins do humano. São Paulo: HUCITEC, 1997.

MAUSS, Marcel. Sociologia e Antropologia. São Paulo : Cosac \& Naify, 2003

PEIRANO, Mariza G. S. A análise antropológica de rituais.Série Antropológica Brasilia: 2000. Prefácio "Rituais como estratégia analítica e abordagem etnográfica" In. O dito e feito: ensaios de Antropologia dos Rituais - Rio de Janeiro: Relume Dumará, 2001.

RIBEIRO, Gustavo Lins. A condição da transnacionalidade. Brasília: UNB, 1997. Disponível em: <http://www.unb.br/ics/dan/Serie223empdf.pdf $>$ acesso em novembro de 2009. 
RAMOS, Alcida Rita. Ethnology Brazilian Style, Cultural Anthropology, 1990.

SAID, W. Edward. Orientalismo: o oriente como invenção do ocidente. Tradução Rosaura Eichenberg. - São Paulo: Companhia das Letras, 2007.

SILVA, Joana A. Fernandes. Território e fronteiras Brasil-Bolivia no país dos Chiquitanos. Revista do Museu Antropológico, v.5/6 ,jan./dez. 2001-2002.

SILVA, Joana. A. F., ROCHA, Leandro. M., SALOMON, M. (Orgs.). Processos de Territorialização: entre a história e a antropologia. Goiânia: UCG, 2005.

TURNER, Victor Witter. Forest of symbols: Aspects of ndembu ritual(the). Ithaca: Cornell Univ Press 405 p.

TURNER, Victor Witter .Celebration: Studies in festivity and ritual. Washington: Smithsonian Inst 